\title{
Effects of Cycloartenol on Absorption and Serum Levels of Cholesterol in Rats
}

\author{
Ikuo IKEDA, Katsuko NAKASHIMA-YoshIDA, and Michihiro SUGANO ${ }^{1}$ \\ Laboratory of Nutrition Chemistry, Kyushu University School of Agriculture, \\ 46-09, Fukuoka 812, Japan
}

(Received November 13, 1984)

\begin{abstract}
Summary The possibility that cycloartenol magnifies the hypocholesterolemic effect of $\beta$-sitosterol was studied in two strains of rats fed on cholesterol-enriched $(0.5 \%)$ diets. Cycloartenol was added to diets containing $1.0 \%$ or $0.5 \% \beta$-sitosterol at the $0.05 \%$ level and to diet free of plant sterol at the $0.5 \%$ level. In one experiment, diets included sodium cholate $(0.125 \%)$. Due to the potent hypocholesterolemic efficacy of $\beta$ sitosterol under the present dietary regimens, no clear additional effect (socalled synergistic effect) of cycloartenol was observed. However, in the experiment using Wistar rats, the decrease in serum apo A-I due to feeding cholesterol was ameliorated more effectively in combination with $\beta$ sitosterol than with $\beta$-sitosterol alone. The hepatic deposition of cholesterol was mitigated by dietary $\beta$-sitosterol, and further, although slightly, by a combination of $\beta$-sitosterol and cycloartenol, except in the experiment with diets containing sodium cholate. Fecal excretion of neutral and acidic steroids was not meaningly magnified by cycloartenol. Cycloartenol itself was not as effective as $\beta$-sitosterol in mitigating lipid disorders due to dietary cholesterol. The rate of appearance of cholesterol in the thoracic duct lymph was not interfered with further by a combination of $\beta$ sitosterol and cycloartenol compared to $\beta$-sitosterol alone. This trimethylsterol was absorbed at a rate approximately 4-fold higher than that of $\beta$-sitosterol, though much lower compared to cholesterol. These results suggest a preference for cycloartenol in cholesterol dynamics. However, cycloartenol seems unlikely to influence cholesterol absorption in the small intestine.
\end{abstract}

Key Words cycloartenol, $\beta$-sitosterol, cholesterol absorption, hypocholesterolemic agent

By comparing the difference in the hypocholesterolemic efficacy of crude and purified soy bean sterol fractions, Kaneda and his colleagues $(1)$ recently showed in rats the synergistic function of trimethylsterols, minor components of crude sterol.

1 池田郁男, 吉田克子, 菅野道廣 
Cycloartenol, when added to the purified $\beta$-sitosterol preparation at the $5 \%$ level, intensified the cholesterol-lowering action of the plant sterol, whereas cycloartenol by itself was not as effective as $\beta$-sitosterol. The above workers provided the evidence, albeit inconclusive, that augmented fecal excretion of neutral sterols might be responsible for its mode of action.

Since cycloartenol is effective at an extremely low level, it seems unlikely that this sterol influences the absorption of cholesterol and/or $\beta$-sitosterol in the intraluminal site, and rather the postabsorptive effect would be more appropriate (2). The aim of the present studies is to reconfirm the so-called synergistic ability of cycloartenol on the one hand and to investigate the rate of intestinal absorption of this trimethysterol and its effect on cholesterol absorption on the other.

\section{MATERIALS AND METHODS}

Animals and diets. Male Wistar and Sprague-Dawley rats were used for feeding studies.The animals were obtained from Kyudo Co., Kumamoto and Seiwa Experimental Animals Co., Ohita, respectively. Rats were housed individually in an air-conditioned room (at $20-23^{\circ} \mathrm{C}$, lights on $08: 00-20: 00 \mathrm{~h}$ ) and given experimental diets and water freely for 28, 29 and 14 days in Experiments I, II and III, respectively. The composition of diets is shown in Table 1. Feed consumption and body weight were recorded three times a week.

Lymph collection. For collection of lymph, male Sprague-Dawley rats weighing 310-340 g and maintained on a commercial non-purified diet (rat chow NMF, Oriental Yeast Co., Tokyo) were used. Under pentobarbital anesthesia $(50 \mathrm{mg} / \mathrm{kg})$, animals were subjected to cannulation of the left thoracic lymphatic cephalad to the cysterna chyli. A second indwelling catheter was placed in the stomach just below the esophagus for administration of the test materials. Animals were placed in restraining cages overnight with free access to $5 \%$ glucose in

Table 1. Composition of the basal diet.

\begin{tabular}{ll}
\hline \multicolumn{1}{c}{ Ingredients } & \multicolumn{1}{c}{$\%$} \\
\hline Casein & 20 \\
Fat $^{1}$ & 10 or 5 \\
Safflower oil & \\
Mineral mixture & 0.5 \\
Vitamin mixture & 4 \\
Choline chloride & 1 \\
Cellulose powder $^{2}$ & 0.15 \\
Sucrose $^{3}$ & 4 \\
\hline
\end{tabular}

${ }^{1}$ Exps. I and II, butter fat $10 \%$; Exp III, safflower oil 5\%. ${ }^{2}$ Includes appropriate amounts of fat-soluble vitamins; A, D and E. ${ }^{3}$ Sterols were added at the expense of sucrose. 
physiological saline. Between $09: 00$ to $10: 00 \mathrm{~h}$, each animal was administered $3 \mathrm{ml}$ of the test emulsion via the indwelling stomach catheter and the lymph was collected at 4-h intervals for $12 \mathrm{~h}$ in heparinized tubes $(500 \mathrm{U} /$ tube). The test emulsions used for intragastric administration were prepared by sonicating for $5 \mathrm{~min}$ and included the following common components per $3 \mathrm{ml}$ physiological saline: $140 \mathrm{mg}$ sodium taurocholate (Calbiochem, La Jolla, CA), $110 \mathrm{mg}$ oleic acid (Tokyo Kasei Co., Tokyo) and $50 \mathrm{mg}$ bovine serum albumin (Sigma Chemical Co., St.Louis, MO) (3). In addition, the emulsions included either $50 \mathrm{mg} \beta$-sitosterol, $50 \mathrm{mg}$ cycloartenol, $50 \mathrm{mg}$ sterol mixtures $(25 \mathrm{mg}$ cholesterol plus $25 \mathrm{mg} \beta$-sitosterol, or $25 \mathrm{mg}$ cholesterol plus $25 \mathrm{mg} \beta$-sitosterol, and $2.5 \mathrm{mg}$ cycloartenol) or $25 \mathrm{mg}$ cholesterol alone. The emulsions were prepared immediately before use and re-homogenized prior to each administration. $\beta$-Sitosterol (ICN Pharmaceuticals, Cleveland, $\mathrm{OH}$ ) was recrystallized from ethyl acetate-methanol to a purity of above $98 \%$, the sterol composition of the preparation being 93\% $\beta$-sitosterol and $7 \%$ campesterol. Cycloartenol was prepared from oryzanol (4) and contained $98 \%$ cycloartenol and $2 \% \beta$-sitosterol.

Lipid analyses. Rats were fasted overnight and killed by decapitation. Serum and liver lipids were extracted and analyzed for cholesterol, triglyceride and phospholipid (5). Serum HDL-cholesterol and apolipoproteins A-I, B and E were analyzed as described elsewhere (6). Feces collected for 2 days prior to killing and lyophilization were analyzed for neutral and acidic steroids by gas-liquid chromatography (7). The lymph was extracted with a chloroform-methanol mixture and sterols were analyzed by gas-liquid chromatography using $5 \alpha$-cholestane as a calibration standard.

Statistical analysis. The results were analyzed by one-way analysis of variance, followed by inspection of all differences between paired means ( 8 ).

\section{RESULTS}

\section{Effects of cycloartenol on serum and liver lipids}

Three sets of experiments were carried out using different strains of rats, Wistar and Sprague-Dawley (Table 2). In each trial, there were no significant differences in the average food intake or weight gains among groups.

In the experiment with Wistar rats (Exp. I), the hypocholesterolemic effect of $\beta$ sitosterol and hence the synergistic effect of cycloartenol could not be observed due to ineffectiveness of dietary cholesterol to elevate serum cholesterol levels. However, the reduction of serum HDL-cholesterol and the increase in liver cholesterol and triglyceride due to cholesterol feeding was ameliorated in the two groups of rats fed $\beta$-sitosterol to a similar extent (Table 3 ). In addition to these observations serum apo A-I levels tended to increase on feeding $\beta$-sitosterol and the extent of the increase was more prominent in rats fed on cycloartenol in combination with $\beta$-sitosterol. There was a significant decrease in serum apo B and an increase in apo $\mathrm{E}$ on feeding $\beta$-sitosterol but cycloartenol showed no additional effect in these 


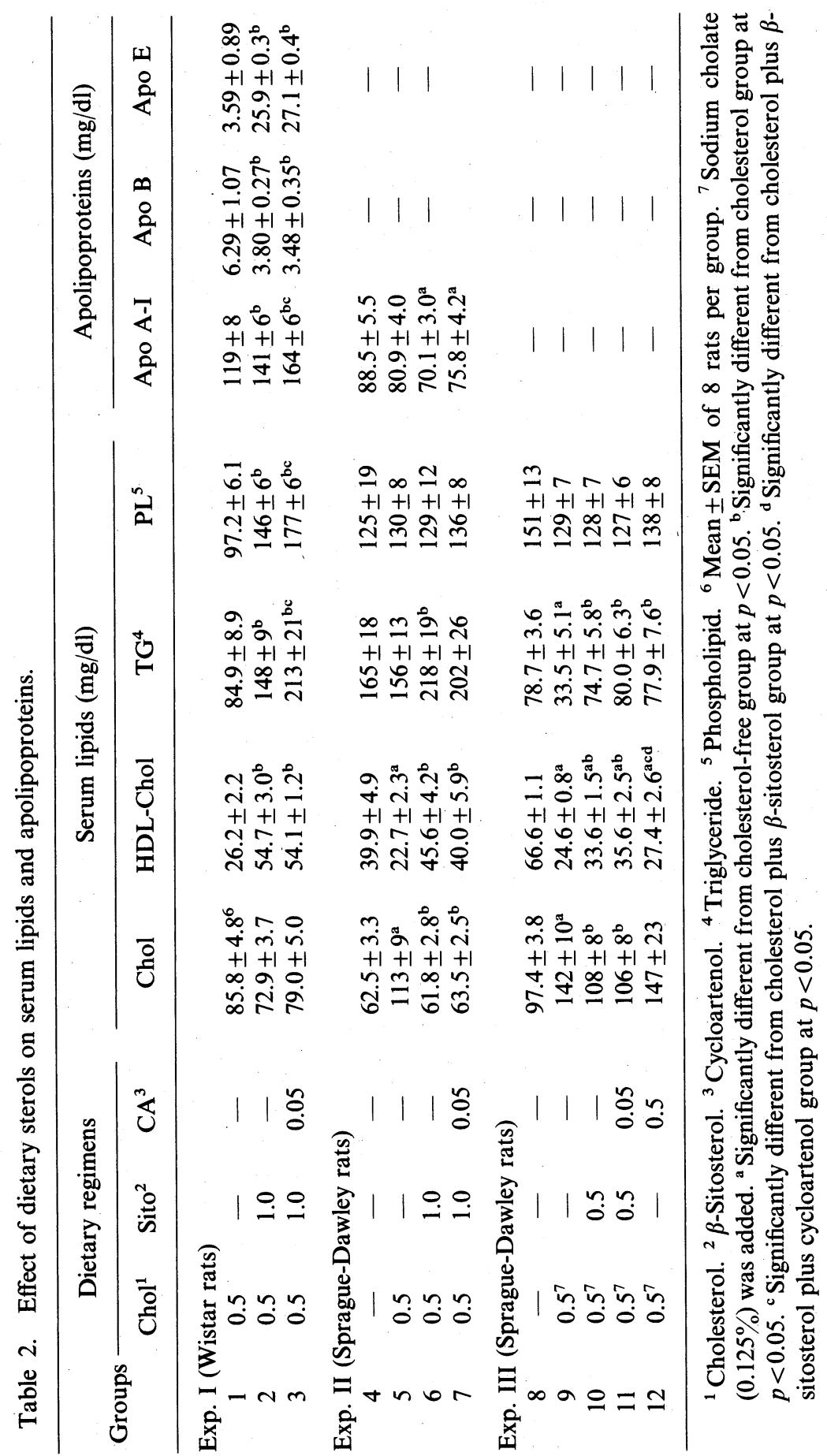


Table 3. Effects of dietary sterols on liver lipids.

\begin{tabular}{rllll}
\hline & \multirow{2}{*}{$\begin{array}{c}\text { Liver weight } \\
\text { (g/100 g body } \\
\text { weight })\end{array}$} & Cholesterol & Triglyceride & Phospholipids \\
\cline { 3 - 5 } & & & & \\
& & & & \\
Exp. I & & & & \\
1 & $3.80 \pm 0.06^{1}$ & $24.4 \pm 1.9$ & $33.0 \pm 2.1$ & $35.4 \pm 1.3$ \\
2 & $3.50 \pm 0.06^{\mathrm{b}}$ & $3.33 \pm 0.20^{\mathrm{b}}$ & $17.1 \pm 1.1^{\mathrm{b}}$ & $34.8 \pm 1.6$ \\
3 & $3.62 \pm 0.09$ & $2.86 \pm 0.17^{\mathrm{b}}$ & $17.8 \pm 1.4^{\mathrm{b}}$ & $38.2 \pm 1.4$ \\
Exp. II & & & & \\
4 & $3.24 \pm 0.09$ & $3.53 \pm 0.10$ & $20.8 \pm 2.3$ & $38.8 \pm 0.5$ \\
5 & $3.40 \pm 0.09$ & $13.8 \pm 2.0^{\mathrm{a}}$ & $19.4 \pm 1.6$ & $36.4 \pm 0.7$ \\
6 & $3.22 \pm 0.07$ & $3.27 \pm 0.18^{\mathrm{b}}$ & $21.1 \pm 2.8$ & $38.2 \pm 0.7$ \\
7 & $3.30 \pm 0.07$ & $2.99 \pm 0.10^{\mathrm{b}}$ & $20.6 \pm 2.1$ & $38.2 \pm 0.8$ \\
Exp. III & & & & \\
8 & $3.64 \pm 0.05$ & $3.32 \pm 0.05$ & $3.64 \pm 0.39$ & $36.8 \pm 0.9$ \\
9 & $4.73 \pm 0.14^{\mathrm{a}}$ & $60.6 \pm 2.9^{\mathrm{a}}$ & $19.7 \pm 3.3^{\mathrm{a}}$ & $34.0 \pm 1.7^{\mathrm{a}}$ \\
10 & $4.07 \pm 0.12^{\mathrm{ab}}$ & $20.9 \pm 2.0^{\mathrm{ab}}$ & $13.8 \pm 2.3^{\mathrm{a}}$ & $35.5 \pm 0.5$ \\
11 & $4.12 \pm 0.04^{\mathrm{ab}}$ & $20.3 \pm 1.4^{\mathrm{ab}}$ & $10.8 \pm 3.3^{\mathrm{b}}$ & $34.1 \pm 0.4^{\mathrm{a}}$ \\
12 & $4.64 \pm 0.06^{\mathrm{acd}}$ & $35.5 \pm 1.3^{\mathrm{abcd}}$ & $10.8 \pm 2.0^{\mathrm{b}}$ & $32.2 \pm 0.5^{\mathrm{ac}}$ \\
\hline
\end{tabular}

${ }^{1}$ Mean \pm SEM of 8 rats per group. ${ }^{\text {a }}$ Significantly different from cholesterol-free group at $p<0.05$. ${ }^{\mathrm{b}}$ Significantly different from cholesterol group at $p<0.05$. ' Significantly different from cholesterol plus $\beta$-sitosterol group at $p<0.05$. ${ }^{\mathrm{d}}$ Significantly different from cholesterol plus $\beta$-sitosterol plus cycloartenol group at $p<0.05$.

parameters. Serum triglyceride levels tended to be increased by $\beta$-sitosterol and it was further magnified by cycloartenol.

In a similar type of experiment with Sprague-Dawley rats (Exp. II), cholesterol feeding caused mild hypercholesterolemia. $\beta$-Sitosterol reduced serum cholesterol to the level observed in rats fed on the diet free of cholesterol, but again no additional reduction was found with the supplementation of cycloartenol. Cholesterol accumulation in the liver was completely prevented by $\beta$-sitosterol and slightly by cycloartenol. In contrast to the observation with Wistar rats, $\beta$-sitosterol or $\beta$-sitosterol plus cycloartenol showed no effect of increasing serum apo A-I levels; rather, there was a decreasing trend.

In the rats fed on diets containing sodium cholate (Exp. III), the hypocholesterolemic efficacy of $\beta$-sitosterol and cycloartenol in combination was virtually the same as that of $\beta$-sitosterol alone. Cycloartenol itself had no cholesterol-lowering activity. The cholesterol content of the liver was decreased by the addition of $\beta$-sitosterol alone or both $\beta$-sitosterol and cycloartenol to the same extent. Cycloartenol by itself decreased the liver cholesterol content, but to a lesser extent than did $\beta$-sitosterol. 
Table 4. Effects of dietary sterols on fecal steroid excretion.

\begin{tabular}{|c|c|c|c|c|c|c|}
\hline \multirow{3}{*}{ Groups } & \multirow{3}{*}{$\begin{array}{c}\text { Feces } \\
\text { excreted } \\
(\mathrm{g} / \text { day })\end{array}$} & \multicolumn{5}{|c|}{ Steroids excreted (mg/day) } \\
\hline & & \multicolumn{4}{|c|}{ Neutral steroids } & \multirow{2}{*}{$\begin{array}{l}\text { Acidic } \\
\text { steroids }\end{array}$} \\
\hline & & Animal $^{1}$ & Plant $^{1}$ & $\begin{array}{c}\text { Animal } / \\
\text { Plant }\end{array}$ & $\begin{array}{c}\text { Cycloar- } \\
\text { tenol }\end{array}$ & \\
\hline \multicolumn{7}{|l|}{ Exp. I } \\
\hline 1 & $1.49 \pm 0.04^{2}$ & $69.2 \pm 3.7$ & $3.5 \pm 0.3$ & - & - & $30.0 \pm 2.0$ \\
\hline 2 & $1.81 \pm 0.11^{\mathrm{b}}$ & $102 \pm 5.8^{b}$ & $220 \pm 11$ & 0.46 & - & $11.3 \pm 0.7^{\mathrm{b}}$ \\
\hline 3 & $1.94 \pm 0.07^{b}$ & $111 \pm 3.4^{b}$ & $236 \pm 8$ & 0.47 & tr. & $11.3 \pm 0.6^{\mathrm{b}}$ \\
\hline \multicolumn{7}{|c|}{ Exp. II } \\
\hline 4 & $1.12 \pm 0.05$ & $14.0 \pm 2.4$ & $5.2 \pm 0.4$ & - & - & $2.6 \pm 0.1$ \\
\hline 5 & $1.26 \pm 0.04^{\mathrm{a}}$ & $67.3 \pm 2.5^{\mathrm{a}}$ & tr. & - & - & $14.4 \pm 3.0^{\mathrm{a}}$ \\
\hline 6 & $1.47 \pm 0.09^{\mathrm{a}}$ & $85.3 \pm 4.6^{\mathrm{ab}}$ & $175 \pm 9$ & 0.49 & - & $8.4 \pm 1.0^{\mathrm{ab}}$ \\
\hline 7 & $1.58 \pm 0.06^{\mathrm{ab}}$ & $84.8 \pm 4.6^{\mathrm{ab}}$ & $176 \pm 10$ & 0.48 & $\operatorname{tr}$. & $7.8 \pm 0.4^{\mathrm{ab}}$ \\
\hline \multicolumn{7}{|c|}{ Exp.III } \\
\hline 8 & $0.96 \pm 0.06$ & $4.8 \pm 0.5$ & $3.1 \pm 0.2$ & - & - & $1.9 \pm 0.4$ \\
\hline 9 & $1.14 \pm 0.07^{\mathrm{a}}$ & $48.8 \pm 2.3^{\mathrm{a}}$ & tr. & - & - & $25.3 \pm 2.6^{\mathrm{a}}$ \\
\hline 10 & $1.13 \pm 0.03^{\mathrm{a}}$ & $85.4 \pm 3.6^{\mathrm{ab}}$ & $107 \pm 3$ & 0.80 & - & $22.3 \pm 1.3^{\mathrm{a}}$ \\
\hline 11 & $1.31 \pm 0.06^{\mathrm{abc}}$ & $95.7 \pm 6.8^{\mathrm{ab}}$ & $119 \pm 6$ & 0.80 & $\operatorname{tr}$. & $27.5 \pm 2.7^{\mathrm{ac}}$ \\
\hline 12 & $1.34 \pm 0.06^{\mathrm{abc}}$ & $71.2 \pm 3.3^{\mathrm{abcd}}$ & tr. & - & $83.1 \pm 3.2$ & $21.5 \pm 0.5^{\mathrm{ad}}$ \\
\hline
\end{tabular}

${ }^{1}$ Includes sterol and copro compounds. ${ }^{2}$ Mean \pm SEM of 8 rats per group. ${ }^{a}$ Significantly different from cholesterol-free group at $p<0.05$. ${ }^{\mathrm{b}}$ Significantly different from cholesterol group at $p<0.05$. ' Significantly different from cholesterol plus $\beta$ sitosterol group at $p<0.05$. ${ }^{\mathrm{d}}$ Significantly different from cholesterol plus $\beta$-sitosterol plus cycloartenol group at $p<0.05$.

\section{Effects of cycloartenol on fecal steroid excretion}

As shown in Table 4, the inhibition of cholesterol absorption by $\beta$-sitosterol was apparent in each experiment. Although cycloartenol in combination with $\beta$ sitosterol seemingly increased the excretion of cholesterol in Exps. I and III, the ratios of animal sterols/plant sterols were almost the same as those observed for the $\beta$-sitosterol group. Thus, the apparent increase in cholesterol excretion in the $\beta$ sitosterol plus cycloartenol group was ascribed to a temporary increase in food intake. Cycloartenol itself was less effective than $\beta$-sitosterol in enhancing fecal sterol excretion. Although $\beta$-sitosterol markedly reduced bacterial transformation of cholesterol to coprostanol, cycloartenol again showed additional effects neither on this conversion nor on the transformation of $\beta$-sitosterol to coprositostanol (data not shown).

The addition of $\beta$-sitosterol or $\beta$-sitosterol plus cycloartenol to a cholesterolenriched diet resulted in a significant reduction of acidic steroid excretion in experiments with diets free of bile salt. In Exp. III, acidic steroid excretion was not necessarily decreased. The addition of $\beta$-sitosterol plus cycloartenol rather increas- 
ed the excretion of acidic steroids.

\section{Lymphatic absorption of sterols}

The intragastric administration of several sterols in emulsion to rats had virtually no effect on the flow rate of thoracic duct lymph (flow rate range $3.5-5.5 \mathrm{ml} / \mathrm{h}$ ). Approximately $50 \%$ of administered cholesterol was absorbed with biphasal absorption patterns for $24 \mathrm{~h}$ under the present experimental conditions
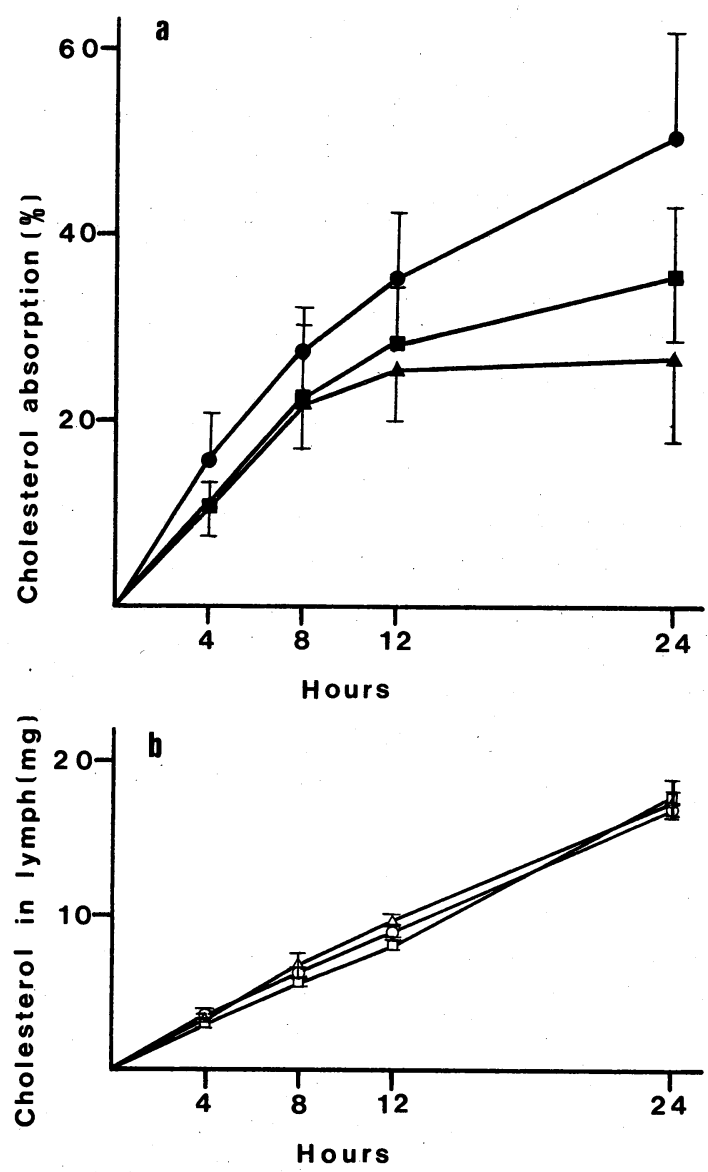

Fig. 1. Lymphatic absorption of cholesterol in rats administered cholesterol containing (a) and cholesterol-free (b) emulsions. Rats received emulsions containing either

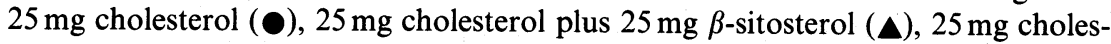
terol plus $25 \mathrm{mg} \beta$-sitosterol plus $2.5 \mathrm{mg}$ cycloartenol $(\boldsymbol{\square}), 50 \mathrm{mg} \beta$-sitosterol ( $\square$ ) or $50 \mathrm{mg}$ cycloartenol $(\triangle)$. Control group $(\bigcirc)$ received sterol-free emulsion. Apparent cholesterol absorption $(\%)$ was calculated according to the following equation; apparent absorption $(\%)=($ cholesterol in lymph $(\mathrm{mg})$-cholesterol in lymph in control group $(\mathrm{mg})) \times 100 /$ cholesterol administered $(\mathrm{mg})$. Data are means of 4 rats \pm SEM.

Vol. 31, No. 3, 1985 


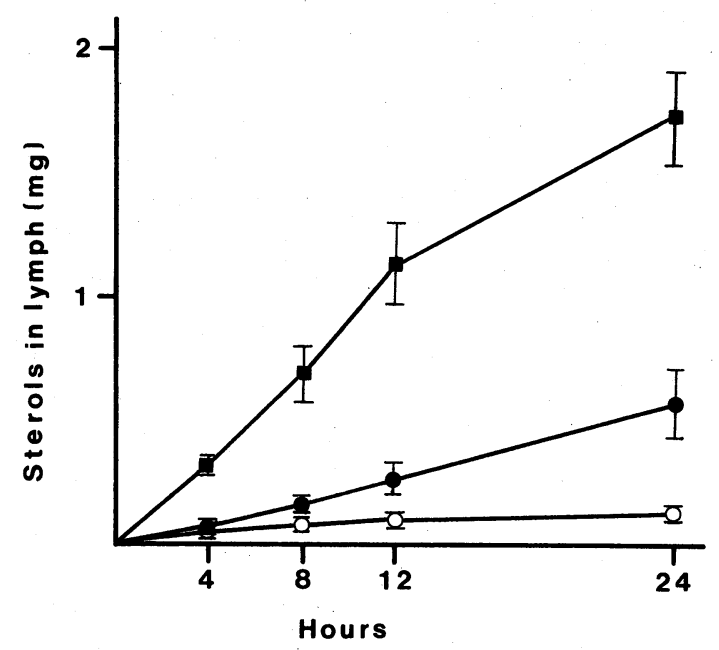

Fig. 2. Lymphatic absorption of cycloartenol and $\beta$-sitosterol. Rats received $50 \mathrm{mg}$ cycloartenol $(\square)$ or $\beta$-sitosterol $(\bullet) . \bigcirc, \beta$-sitosterol in rats receiving sterol-free emulsion. Data are means of 4 rats \pm SEM.

(Fig. 1a). $\beta$-Sitosterol reduced the absorption of exogenous cholesterol to about $1 / 2$ that observed with cholesterol alone, but additional cycloartenol showed no further reducing effect. However, when $\beta$-sitosterol or $\beta$-sitosterol plus cycloartenol were administered in the absence of exogenous cholesterol, these sterols in no way influenced the appearance of endogenous cholesterol in the lymph (Fig. 1b).

Figure 2 illustrates that cycloartenol was absorbed at a 4-fold higher rate than that of $\beta$-sitosterol, although the absolute figure for the former was markedly small, less than $4 \%$, over $24 \mathrm{~h}$.

Sterol and fatty acid compositions of tissue lipids

Serum and liver were analyzed for sterol and fatty acid compositions in Exps. I and II. Sera from two strains of rats fed cholesterol plus $\beta$-sitosterol contained $11-13 \%$ plant sterols of which approximately $80 \%$ was $\beta$-sitosterol. No cycloartenol was detected.

Analyses of serum and liver total lipids revealed that changes in fatty acid profiles due to feeding cholesterol, the decrease in percentage of stearic and arachidonic acid and the increase in that of palmitoleic and oleic acid, were ameliorated by the supplementation of $\beta$-sitosterol. Further addition of cycloartenol, however, showed no additional effects on these parameters. Very comparable results were obtained with total liver lipids.

\section{DISCUSSION}

The present studies failed to demonstrate a so-called synergistic hypocholes- 
terolemic effect of cycloartenol. The inconsistency with Kiribuchi's observation ( 1 ) can in part be ascribed to the lower hypercholesterolemic response of our animals. Cholesterol feeding in fact increased liver cholesterol but did not elevate serum cholesterol to a hypercholesterolemic level, even when the diet contained both cholesterol and bile salt. In addition, the hypocholesterolemic effect of $\beta$-sitosterol was so potent that the additional possible effect of cycloartenol might be cancelled out. However, analyses of serum apolipoprotein indicated a possible effect of cycloartenol. Thus, in Wistar rats, trimethylsterol increased serum apo A-I more markedly than did $\beta$-sitosterol alone; this was not the case for Sprague-Dawley rats. Also, liver cholesterol levels tended to be decreased by cycloartenol, except for the experiment with diets containing bile salt (Exp. III). It seems therefore likely that cycloartenol has some additional effect(s) on the hypocholesterolemic action of $\beta$ sitosterol.

If cycloartenol is effective, it should exert its effect through either interference with (a) the absorption of cholesterol or (b) the postabsorptive process. Though Kiribuchi et al.(l) demonstrated an increased fecal output of neutral steroids caused by cycloartenol, it seems difficult to interpret how this minimal amount of cycloartenol in relation to $\beta$-sitosterol exerts the synergistic effect, since we have demonstrated that the inhibition of cholesterol absorption by $\beta$-sitosterol is almost entirely ascribed to the limitation of micellar solubilization of cholesterol (9). Hence, if cycloartenol exhibits its action in the intestinal lumen, the trimethylsterol should interfere with absorption of cholesterol at the surface of absorptive cells. Though still not generally accepted, the possible existence of binding protein, which is specific for cholesterol but not for plant sterols, in the brush border membrane of the epithelial cells has been hypothesized (10). One might assume that cycloartenol combines with such a receptor protein in preference to cholesterol and hence reduces cholesterol absorption. However, this possibility is unlikely since (a) the fecal excretion of cholesterol was not affected by cycloartenol, (b) cycloartenol alone was not as effective as $\beta$-sitosterol in ameliorating hypercholesterolemia at the same dietary level and (c) lymphatic absorption of cholesterol was not further inhibited by the combination of $\beta$-sitosterol and cycloartenol compared to $\beta$ sitosterol alone.

Alternatively, cycloartenol may exert its effect after it is being absorbed. Though the rate of absorption of cycloartenol was indeed lower than that of cholesterol, it is still absorbed at a higher rate than is $\beta$-sitosterol. $\beta$-Sitosterol has been shown to have some postabsorptive effect though it is absorbed only marginally(11). Because cycloartenol was absorbed more effectively than $\beta$ sitosterol, a postabsorptive effect cannot be ignored if this sterol has a long metabolic fate or, more directly, has a specific metabolic effect(s). In this context, Kitahara and Kaneda (2) suggested an inhibitory effect on cholesterol biosynthesis and a hormone-like effect of cycloartenol in the rat.

From these considerations, more studies are required to establish the synergistic effect of cycloartenol on the absorption and metabolism of cholesterol. Several 
studies with rats and humans have indicated that $\gamma$-oryzanol has a hypocholesterolemic effect $(12,13)$. Since $\gamma$-oryzanol is rich in trimethylsterols such as cycloartenol and 24-methylenecycloartenol(14), there seems to be some connection with the synergistic effect of cycloartenol. However, $\gamma$-oryzanol is thought to be absorbed intact, though at an extremely low rate, and then exert its cholesterol-lowering effect (12).

Cycloartenol and $\gamma$-oryzanol were kindly provided by Ohtsuka Pharmaceutical Co., Tokushima and Riken Vitamin Co., Ltd., Tokyo, respectively. Butter fat was a gift from Snow Brand Milk Co., Tokyo.

\section{REFERENCES}

1) Kiribuchi, M., Miura, K., Tokuda, S., and Kaneda, T. (1983): Hypocholesterolemic effect of triterpene alcohols with soy sterol on plasma cholesterol in rats. J. Nutr. Sci. Vitaminol., 29, 35-43.

2) Kitahara, M., and Kaneda, T. (1984): Effect of cycloartenol on cholesterol metabolism in rats. Vitamins (in Japanese), 58, 239.

3) Vahouny, G. V., Fawal, I., and Treadwell, C. R. (1957): Factors facilitating cholesterol absorption from the intestine via lymphatic pathways. Am. J. Physiol., 188, 342-346.

4) Endo, T., Misu, O., and Inaba, Y. (1969): Studies on the ferulates in rice bran oil. $J$. Jpn. Oil Chem. Soc., 18, 63-67.

5) Sugano, M., Kamo, F., Ikeda, I., and Morioka, H. (1976): Lipid-lowering activity of phytostanols in rats. Atherosclerosis, 24, 301-309.

6) Imaizumi, K., Murata, M., and Sugano, M. (1982): Effect of dietary polyunsaturated phospholipid on the chemical composition of serum lipoproteins in rat. J. Nutr. Sci. Vitaminol., 28, 281-294.

7) Sugano, M., Fujikawa, T., Hiratsuji, Y., Nakashima, K., Fukuda, N., and Hasegawa, Y. (1980): A novel use of chitosan as a hypocholesterolemic agent in rats. Am. J. Clin. Nutr., 33, 787-793.

8) Snedecor, G. W., and Cochran, W. G. (1967): Statistical Methods, 6th Ed., Iowa State University Press, Ames, Iowa, pp. 258-298.

9) Ikeda, I., and Sugano, M. (1983): Some aspects of mechanism of inhibition of cholesterol absorption by $\beta$-sitosterol. Biochim. Biophys. Acta, 732, 651-658.

10) Glover, J., and Green, C. (1957): Sterol metabolism. 3. The distribution and transport of sterols across the intestinal mucosa of the guinea pig. Biochem. J., 67, 308-315.

11) Beveridge, J. M. R., Connell, W. F., Mayer, G. A., and Haust, H. L. (1958): Plant sterols, degree of unsaturation, and hypocholesterolemic action of certain fats. Can. J. Biochem. Physiol., 36, 859-911.

12) Shinomiya, M., Morisaki, N., Matsuoka, N., Izumi, S., Saito, Y., Kumagai, A., Mitani, K., and Morita, S. (1983): Effect of $\gamma$-oryzanol on lipid metabolism in rats fed highcholesterol diet. Tohoku J. Exp. Med., 141, 191-197.

13) Orimo, H. (1982): Lipid-lowering effect of $\gamma$-oryzanol in man-A single blind study (abstract). 6th Int. Symp. Atherosclerosis, p. 236.

14) Noda, H., Shimizu, T., and Higuchi, K. (1974): Studies on absorption, tissue distribution, metabolism and excretion of ferulic acid triterpene-alcohol ester $(\gamma$ oryzanol). Part II. Clin. Rep. (in Japanese), 8, 35-42. 